\title{
Análise física e química de águas de coco, industrializadas e in natura, comercializadas no Município de João Pessoa, Paraíba, Brasil
}

\section{Homero Perazzo Barbosa ${ }^{1}$, Carolina Uchôa Guerra Barbosa de Lima1, Amanda Justino Costa ${ }^{2}$, Ana Luíza Nóbrega Freire Gaudêncio Cardoso ${ }^{2}$, Paulo Victor Sarmento Dias ${ }^{2}$ e Eduardo Uchôa Guerra Barbosa ${ }^{2}$}

\author{
${ }^{1}$ Faculdade de Medicina Nova Esperança. Av. Frei Galvão, 12. Gramame. João \\ Pessoa-PB, Brasil (CEP 58067-698). \\ ${ }^{2}$ Faculdade de Medicina Nova Esperança. Curso de Medicina. Av. Frei Galvão, 12. \\ Gramame. João Pessoa-PB, Brasil (CEP 58067-698). *E-mail: \\ eduardouchoa@hotmail.com.
}

Resumo. O Brasil é um grande produtor e também apresenta significativo consumo de água de coco, que é uma bebida de elevado valor nutritivo. Este artigo teve por objetivo avaliar algumas características físicas e químicas (acidez total titulável (AT), açúcar total, $\mathrm{pH}$, sólidos solúveis, densidade, bem como razão entre sólidos solúveis e acidez total titulável), em oito amostras de água de coco, comercializadas no Município de João Pessoa-PB, sendo seis industrializadas e duas in natura. Os dados obtidos foram submetidos à análise de variância utilizando-se o teste $\mathrm{F}$ e as médias comparadas pelo teste de Scott-Knott a 5\% de probabilidade. Houve diferença significativa entre as amostras analisadas $(\mathrm{P}<0,05)$ para todas as variáveis estudadas, exceto para a densidade. No entanto, os resultados das análises mostram que os produtos comercializados estão de acordo com os padrões estabelecidos pela legislação vigente para a água de coco.

Palavras-chave: Cocos nucifera; Bebida não alcoólica; Análise física e química; Padrão de qualidade; Legislação em saúde.

Abstract. Physicochemical analysis of coconut water, processed and in natura sold in the Municipality of João Pessoa, Paraíba, Brasil. Brazil is a great producer and also has a significant consumption of coconut water, which is a drink that has a high nutritional value. This study has as objective evaluate some physicochemical characteristics (total titratable acidity, total sugar, $\mathrm{pH}$, soluble solids and density, and the ratio between soluble solids and total titratable acidity), in 8 samples of coconut water, 2 being in natura and 6 processed, sold in the Municipality of João Pessoa (PB). The data obtained were subjected to the
Recebido

$23 / 12 / 2020$

Aceito

$10 / 04 / 2021$

Disponível on line

$12 / 04 / 2021$

Publicado

$30 / 04 / 2021$

Acesso aberto

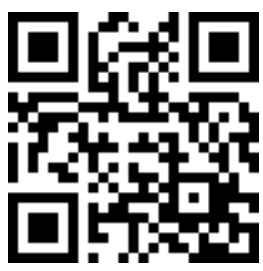

(D) $0000-0003-2976-4066$ Homero Perazzo Barbosa

ISSN 2359-1412/RBGAS-2020-0182/2021/8/18/22/341

Rev. Bras. Gest. Amb. Sustent.

http://revista.ecogestaobrasil.net 
variance analysis using the $\mathrm{F}$ test and the means were compared by the Scott-Knott test at $5 \%$ probability. There was significant difference among the samples analyzed $(\mathrm{P}<0.05)$ in all fields tested, except in density. The result of the analysis are in accordance with the standards established by the current legislation concerning coconut water.

Keywords: Cocos nucifera; Non-alcoholic beverage; Physicochemical analysis; Quality standard; Health legislation.
0000-0001-9703-3156

Carolina Uchôa Guerra

Barbosa de Lima

(D) 0000-0003-1694-3188 Amanda Justino Costa

(D) 0000-0003-1516-8730

Ana Luíza Nóbrega

Freire Gaudêncio

Cardoso

(D) 0000-0003-1382-4028

Paulo Victor Sarmento Dias

(D) 0000-0002-6818-7604

Eduardo Uchôa Guerra

Barbosa

\section{Introdução}

Atualmente, o Brasil é o quinto maior produtor mundial de coco, com 2,3 milhões de toneladas, apesar da redução da área plantada, destacando-se o Nordeste com 178.840 ha de área colhida (Brainer, 2018).

A água de coco é caracterizada por baixo teor de carboidratos e gorduras sendo, dessa forma, uma bebida de baixa caloria (Alves, 2017). Devido à alta concentração de minerais, como potássio e sódio, a água de coco é muito utilizada para reidratação de atletas como uma alternativa natural aos isotônicos comerciais (Froehlich, 2015).

Conforme definido na Instrução Normativa MAPA no 9/2020, a água de coco é a bebida não diluída, não fermentada, obtida da parte líquida do fruto do coqueiro (Cocos nucifera Linnaeus), por meio de processo tecnológico adequado (Brasil, 2020).

Devido a suas características físicas e químicas, diversos estudos foram feitos nos últimos anos para a utilização da água de coco em procedimentos clínico-cirúrgicos, assim como a potencial utilização no tratamento de sepse e choque hipovolêmico (Medeiros, 2017), na prevenção e tratamento de Alzheimer (Fernando et al., 2015) e na conservação de enxertos em procedimentos de transplante (César et al., 2015).

A Instrução Normativa MAPA no 9/2020, que revogou a Instrução Normativa MAPA no 27/2009 (Brasil, 2019), estabelece os padrões de identidade e qualidade para a água de coco, bem como os respectivos parâmetros analíticos. Todas as águas comercializadas devem possuir características sensoriais de aspecto, cor, sabor e odor característicos, e estarem dentro dos parâmetros físico-químicos, com $\mathrm{pH}$ variando de 4,0 a 6,5, e sólidos solúveis ( $\mathrm{em}^{\circ}$ Brix) variando de 4,0 a 29,0 (Brasil, 2020).

Os ácidos orgânicos presentes em alimentos influenciam o sabor, odor, cor, estabilidade e a manutenção de qualidade, onde podem ser determinados pela acidez titulável (Cecchi, 2003). A determinação desse parâmetro em alimentos é bastante importante, já que através dela podem-se obter dados valiosos na avaliação do processamento e do estado de conservação dos alimentos (Instituto Adolfo Lutz, 2008).

0 açúcar é um dos constituintes mais importantes da água de coco, o qual, no início da maturação, se apresenta como açúcares redutores (glicose e frutose). Quando o fruto termina seu processo de maturação, o açúcar total contido em sua água é de aproximadamente 2,0 g/100 mL (Venturini Filho, 2005). 
$\mathrm{O}$ valor de $\mathrm{pH}$ da água de coco varia com a idade do fruto, apresentando-se em torno de 4,7 e 4,8 quando está com a idade de cinco meses, e acima de 5,0 até o final do crescimento do fruto (Aragão et al., 2001). Quando a água de coco for submetida a algum processo tecnológico de conservação, a legislação brasileira permite fazer a correção do pH da água de coco com adição de ácido cítrico (Carvalho et al., 2006).

É importante também conhecer a densidade de um alimento, pois essa medida está diretamente ligada à detecção da sanidade e da qualidade da matéria prima e até mesmo de seu produto final, constituindo uma espécie de controle de qualidade. A densidade aparente é aquela calculada dividindo-se a massa pelo volume aparente da amostra (Sampaio et al., 2007).

O objetivo deste trabalho foi $\mathrm{o}$ de analisar águas de coco in natura e industrializadas, comercializadas no Município de João Pessoa-PB, quanto a sua composição física e química, para caracterizá-las e compará-las com a legislação brasileira vigente.

\section{Material e métodos}

Foram avaliadas a composição física e química de seis marcas industrializadas e duas in natura de águas de coco comercializadas no Município de João Pessoa-PB.

Para as análises, estabeleceu-se como critério de inclusão a coleta de alimentos dentro do prazo de validade e com aspecto físico que permitia o consumo.

As análises de acidez total titulável (\%), de açúcar total (\%), de $\mathrm{pH}$, de sólidos solúveis totais $\left({ }^{\circ}\right.$ Brix) e de densidade $(\mathrm{g} / \mathrm{mL})$ foram realizadas, em triplicata, no Laboratório de Tecnologia Química de Alimentos, do Departamento de Tecnologia Química e de Alimentos (CT/UFPB), de acordo com a metodologia descrita pelo Instituto Adolfo Lutz (2008).

A relação SS/AT foi obtida através do quociente entre sólidos solúveis totais (SS) e acidez total titulável (AT), que serve de indicativo do sabor da água de coco (Imaizume et al., 1976).

As análises estatísticas foram realizadas de acordo com o SISVAR proposto por Ferreira (2014). Os dados obtidos foram submetidos à análise de variância utilizando-se o teste F para comparação dos quadrados médios e indicação da significância dos efeitos de tratamentos (alimentos). As médias foram comparadas pelo teste de Scott-Knott (1974), a $5 \%$ de probabilidade.

\section{Resultados e discussão}

A Tabela 1 apresenta a comparação das médias feitas pelo teste de Scott-Knott (1974), a 5\% de probabilidade (Tabela 1).

Tabela 1. Análise de variância para as diversas variáveis dos alimentos (águas de coco) estudados.

\begin{tabular}{|l|c|c|c|c|c|c|}
\hline \multirow{2}{*}{ Fontes de variação } & \multirow{2}{*}{ GL } & \multicolumn{5}{|c|}{ Quadrados médios } \\
\cline { 3 - 7 } & & AT* $^{*}$ & AÇT* & pH $^{*}$ & oBRIX $^{*}$ & $\mathbf{d}^{\text {NS }}$ \\
\hline Alimentos & 17 & 0,236763 & 1,361095 & 4,132429 & 0.575179 & 5,184524 \\
\hline Erro & 16 & 0,013600 & 0,000967 & 0,0035533 & 0.003333 & 3,333333 \\
\hline CV $(\%)$ & - & 3,49 & 0,91 & 0,29 & 1,06 & 0,18 \\
\hline
\end{tabular}

*Significativo a 5\% de probabilidade, pelo teste de Scott-Knott. NS = Não Significativo. AT = acidez total titulável, $\mathrm{AÇT}=$ açúcar total, $\mathrm{pH}=$ potencial hidrogeniônico, $\mathrm{d}=$ densidade, ${ }^{\circ} \mathrm{BRIX}$ (sólidos solúveis). 
Houve diferença significativa $(\mathrm{P}<0,05)$ entre as amostras para os diversos parâmetros analisados, exceto para a densidade (Tabela 2). Os aspectos físicos e químicos em alimentos devem ser sempre avaliados, devido às reações enzimáticas ocorrentes, sendo importantes na determinação da qualidade do produto alimentício (Silva et al., 2013).

Tabela 2. Médias de Acidez Total Titulável (AT), Açúcar Total (AÇT), pH, ${ }^{\circ}$ BRIX e densidade das marcas estudados.

\begin{tabular}{|c|c|c|c|c|c|c|}
\hline Marcas & $\begin{array}{c}\mathbf{A T} \\
\mathbf{( \% )}\end{array}$ & $\begin{array}{c}\text { AÇT } \\
\mathbf{( \% )}\end{array}$ & $\mathbf{p H}$ & $\begin{array}{c}\text { Sólidos } \\
\left.\text { solúveis ( } \mathbf{}^{\mathbf{B}} \mathbf{B i x}\right)\end{array}$ & $\begin{array}{c}\text { Densidade* }^{*} \\
\mathbf{( g / m L )}\end{array}$ & ${ }^{\circ}$ Brix/AT \\
\hline $\mathrm{A}$ & $1,01^{\mathrm{a}}$ & $3,76^{\mathrm{b}}$ & $4,52^{\mathrm{h}}$ & $5,07^{\mathrm{f}}$ & 1,0176 & 5,02 \\
\hline $\mathrm{B}$ & $0,90^{\mathrm{b}}$ & $3,91^{\mathrm{a}}$ & $4,78^{\mathrm{g}}$ & $5,60^{\mathrm{d}}$ & 1,0176 & 6,22 \\
\hline $\mathrm{C}$ & $0,88^{\mathrm{b}}$ & $3,03^{\mathrm{e}}$ & $5,66^{\mathrm{b}}$ & $5,90^{\mathrm{b}}$ & 1,0193 & 6,70 \\
\hline $\mathrm{D}$ & $0,80^{\mathrm{c}}$ & $3,93^{\mathrm{a}}$ & $5,00^{\mathrm{e}}$ & $5,80^{\mathrm{c}}$ & 1,0203 & 7,25 \\
\hline $\mathrm{E}$ & $0,78^{\mathrm{c}}$ & $3,42^{\mathrm{d}}$ & $5,14^{\mathrm{d}}$ & $5,20^{\mathrm{e}}$ & 1,0173 & 6,67 \\
\hline F & $0,71^{\mathrm{d}}$ & $3,50^{\mathrm{c}}$ & $4,87^{\mathrm{f}}$ & $5,00^{\mathrm{f}}$ & 1,0183 & 7,04 \\
\hline Coco seco & $0,91^{\mathrm{b}}$ & $1,94^{\mathrm{f}}$ & $5,49^{\mathrm{c}}$ & $5,00^{\mathrm{f}}$ & 1,0176 & 5,49 \\
\hline Coco verde & $0,71^{\mathrm{d}}$ & $3,87^{\mathrm{a}}$ & $5,76^{\mathrm{a}}$ & $6,07^{\mathrm{a}}$ & 1,0206 & 8,55 \\
\hline Média & 0,84 & 3,42 & 5,15 & 5,45 & 1,0186 & 6,62 \\
\hline
\end{tabular}

Valores médios, nas colunas, seguidos de mesmas letras não diferem estatisticamente entre si pelo teste de Scott-Knott a 5\% de probabilidade. * Não significativo

A acidez total titulável indica a quantidade de ácido málico (principal ácido orgânico) encontrado na água de coco. Os valores elevados apresentados podem indicar que a matéria-prima utilizada na comercialização estava prematura para a colheita, pois a quantidade de ácidos diminui com o amadurecimento do fruto. Além disso, a acidez é um importante indicador sensorial, pois tem papel fundamental no sabor e aroma da água de coco (Kays, 1991; Charlo et al., 2009; Aroucha et al., 2010).

Os valores de acidez total titulável (Figura 1 ) variaram entre $0,71 \%$ para a marca $F$ e Coco Verde e 1,01\% (marca A). Valores semelhantes foram obtidos por Duarte (2012) em estudo realizado em Ariquemes-RO.

Imaizumi et al. (2016) encontraram valores bem variados de acidez total titulável $(0,23 \%$ a $0,96 \%)$ para a água de coco in natura de diversas cidades do Brasil (sete do Nordeste e seis do Sudeste). Por sua vez, Vasconcelos et al. (2015) determinaram, em amostras coletadas em Mossoró-RN, valores que variaram de 0,67\% a 1,47\%. Costa et al (2005) em pesquisa com água de coco obtida por diferentes métodos de conservação encontraram resultados de $0,06 \%$ a 0,12\%. Lima et al. (2015) analisando amostras provenientes do sertão da Paraíba e do Ceará, determinaram valores variando de 0,03 a 0,07\%. Mendonça et al. (2020) encontraram variação de 0,49 a 2,70\%.

As diferenças dos resultados podem ser justificadas pelo fato de haver variações no clima e no solo de cada região, também devido ao ponto de maturação e armazenamento dos frutos (Oliveira et al., 2003).

$\mathrm{Na}$ análise de açúcar total (Figura 2) as amostras diferiram estatisticamente entre si $(\mathrm{P}<0,05)$ com o menor valor de $1,94 \%$ (coco seco). Os valores obtidos no presente estudo foram inferiores aos obtidos por Imaizume et al. (2016). Pesquisa realizada em Lavras-MG, por Oliveira et al. (2003), encontrou resultados variando de 2,7 a 6,4 g/100 ml. 0 teor de açúcar total decresceu com a idade do fruto, apresentando 1,94\% para a água de coco seco em comparação com a água do coco verde $(3,87 \%)$. As marcas B e D não 
diferiram entre si $(P>0,05)$, concordando com as informações de Carvalho et al. (2006). Pinheiro et al. (2005), pesquisando diversas marcas em Fortaleza-CE, encontraram para açúcar total, valores superiores aos do presente estudo.

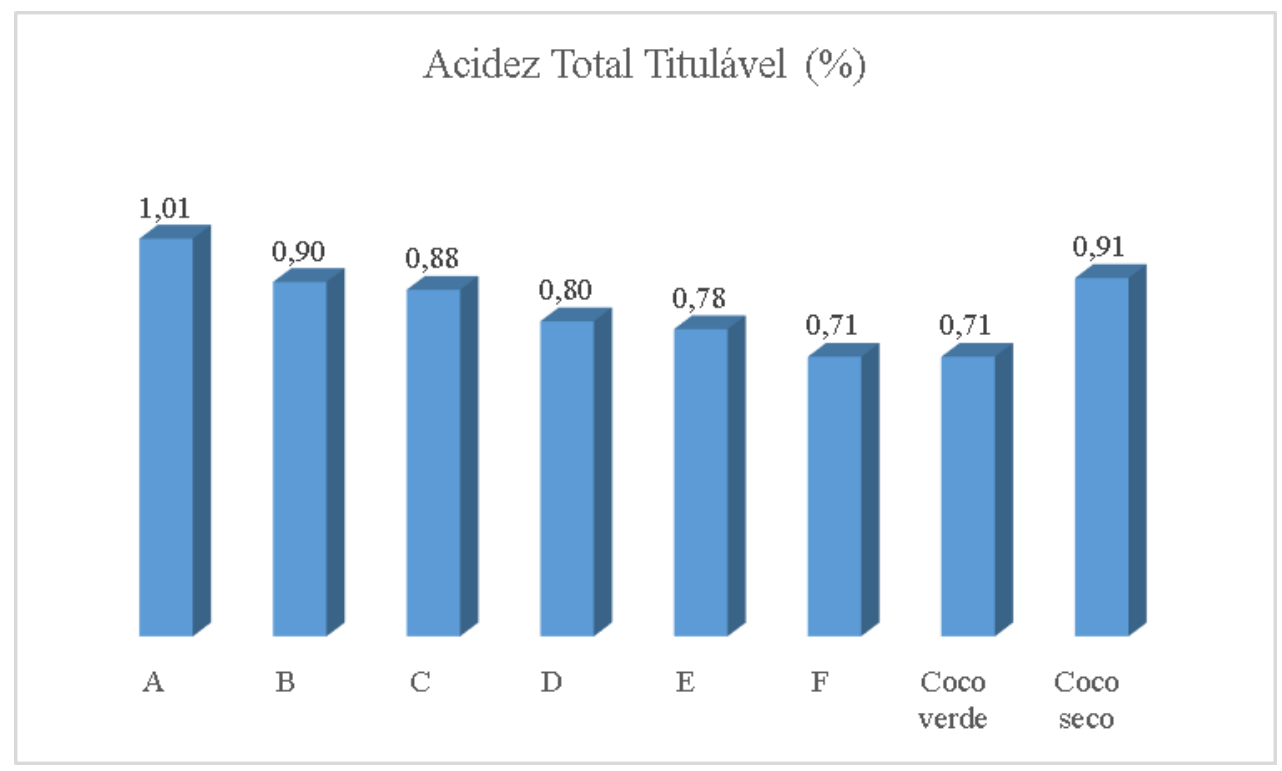

Figura 1. Acidez total titulável nas amostras de água de coco.

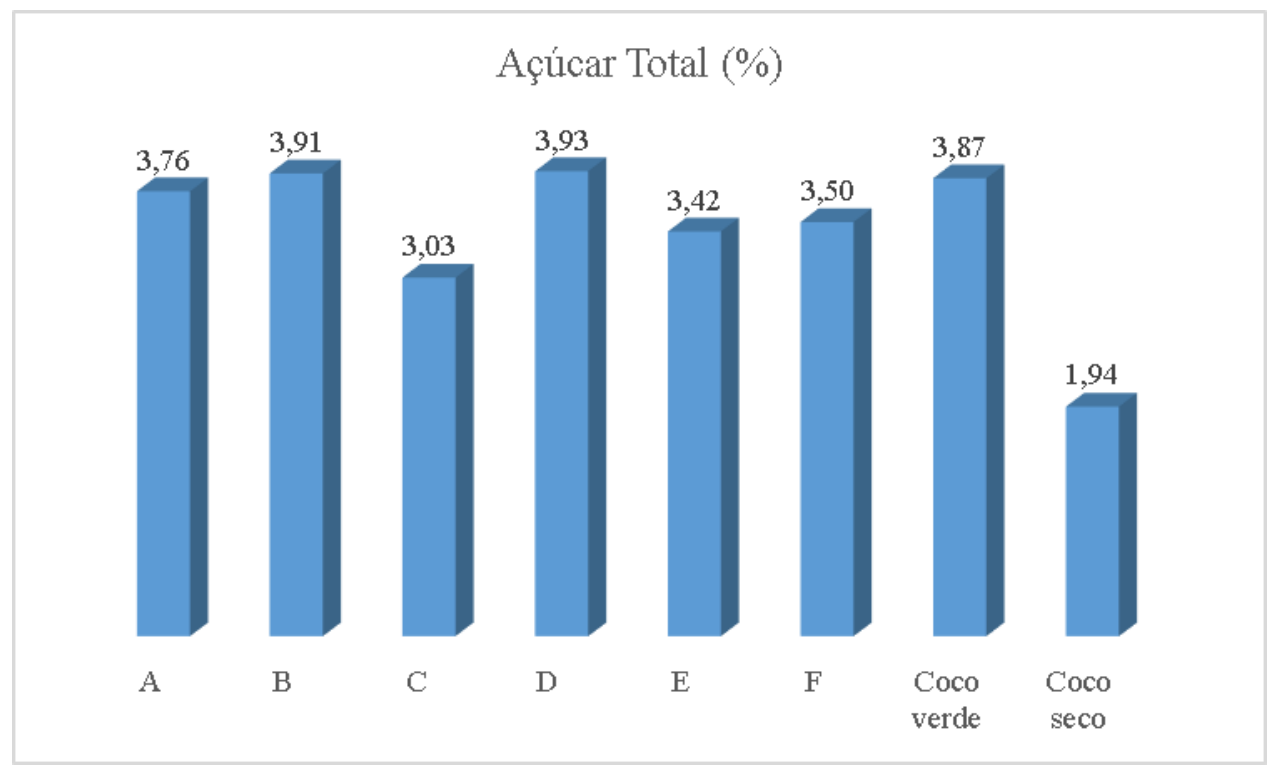

Figura 2. Açúcar total nas amostras de água de coco.

Para as análises de pH observou-se que as amostras avaliadas se apresentaram dentro dos padrões estabelecidos pela Instrução Normativa MAPA no 9/2020 (Brasil, 2020), que estabelece pH mínimo e máximo de 4,0 e 6,5, respectivamente, para água de coco. 0 pH (Tabela 2 e Figura 3) variou entre 4,52 (A) e 5,76 (coco verde). Vasconcelos et al. (2015) encontraram valores de pH variando de 4,84 a 5,97 e Lima et al. (2015) obtiveram resultados semelhantes aos deste estudo. Analisando diversas marcas e amostras in natura em Salgueiro-PE, Alves et al. (2017) encontraram medidas de pH 
variando de 5,02 a 5,19 e Costa et al. (2005) [onde?] de 4,32 a 4,93. Por sua vez, Duarte (2012) em diversas análises encontram uma variação de 4,61 a 4,98 e Rosa et al. (2011), em estudo efetuado no Município de Medianeira-PR, verificaram variação de 4,93 a 5,00. Mendonça et al. (2020) encontraram pH variando de 4,25 a 5,67.

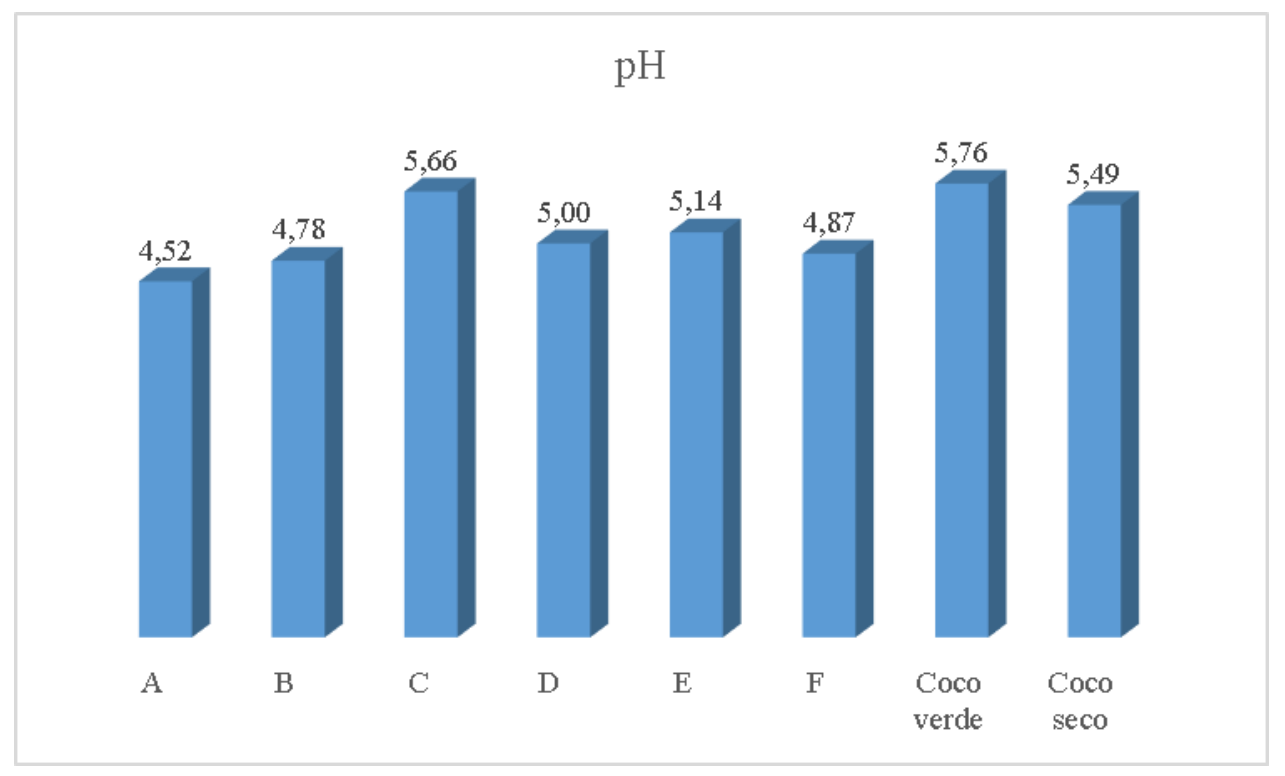

Figura 3. pH nas amostras de água de coco.

Um pH muito elevado pode ser ocasionado por aumento da atividade microbiológica. A avaliação do pH é importante, pois o sabor doce e adstringência desejáveis são atingidos com pH próximos de 5,50 (Nery et al., 2002).

Outro fator relevante é o descrito por Tan et al. (2013), que observaram variação nos valores de pH de águas de coco em diferentes estágios de maturação. A observação desses autores sugere que a indústria pode estar usando cocos em diferentes estágios de maturação.

Segundo Pinheiro et al. (2005), o valor do pH da água de coco verde é maior que o das outras amostras analisadas, concordantes com os encontrados no presente trabalho. Isso pode ser devido, provavelmente, ao fato da adição de ácido cítrico para baixar o $\mathrm{pH}$ visando melhorar sua conservação, e assim, a vida de prateleira (Rosa e Abreu, 2000).

Imaizumi et al. (2016) encontraram valores de $\mathrm{pH}(5,21)$ para água de coco in natura, provenientes de diversas cidades do Brasil. $0 \mathrm{pH}$ da água de coco varia de acordo com a idade do fruto, sendo que, quando a idade é de 5 meses, o pH encontra-se em torno de 4,70 a 4,80 elevando-se acima de 5,00 até o final do crescimento do fruto (Aragão et al., 2001).

0 teor de sólidos solúveis ( ${ }^{\circ} B$ Brix) está diretamente relacionado à doçura e a manifestação do sabor da água de coco uma vez que, em grande percentagem, é representada pelos açúcares, existindo, portanto, uma forte correlação dessa característica com a qualidade final da água (Silva et al., 2015). Os valores de ${ }^{\circ} B r i x$ apresentaram diferença significativa $(\mathrm{P}<0,05)$ entre as amostras avaliadas (Tabela 2 e Figura 4).

A legislação vigente estabelece como valor de ${ }^{\circ}$ Brix o mínimo de 4,0 e o máximo de 29,0 (Brasil, 2020). Os teores obtidos para esse parâmetro se encontram dentro da faixa limite estabelecida, variando de 5,00 a 6,07. Os resultados encontrados evidenciam a qualidade da água, cabendo destacar o valor obtido para a agua de coco verde. Vasconcelos et al. (2015) encontram valores de ${ }^{\circ}$ Brix variando de 4,75 a 6,25, enquanto que Duarte 
(2012) observaram resultados entre 4,36 a 5,36 e Mendonça et al. (2020) entre 4,00 a 6,40 .

Tan et al. (2013) encontraram valores médios de ${ }^{\circ}$ Brix variando de 4,85 a 6,15, em frutos de diferentes estágios de maturação. Silva et al. (2009) analisando águas de coco de cultivo convencional e orgânico, obtidas na Cidade de Trairi-CE, encontraram valores médios de 5,58 ${ }^{\circ}$ Brix para água de coco convencional e $6,00{ }^{\circ}$ Brix para água de coco orgânica. Rosa e Abreu (2000) em uma caracterização físico-química de água de coco obtiveram valor médio de $5,00{ }^{\circ}$ Brix.

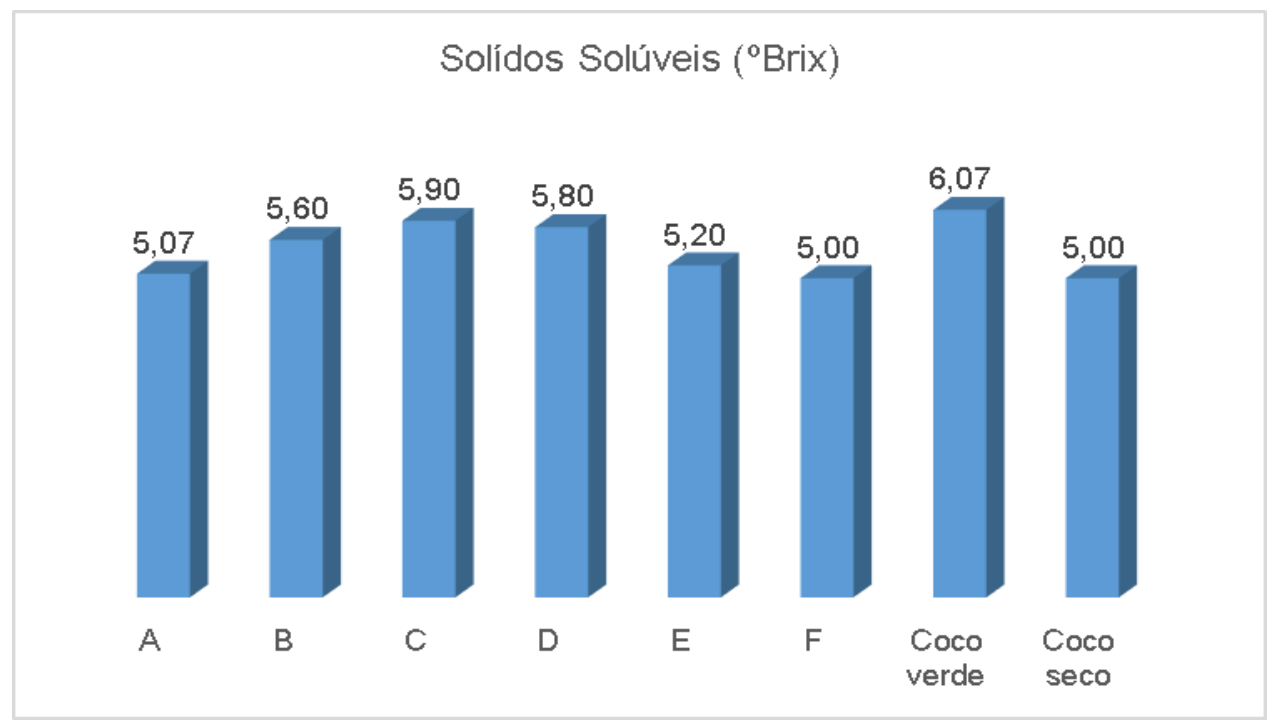

Figura 4. Sólidos solúveis ( ${ }^{\circ}$ Brix) nas amostras de água de coco.

Valores semelhantes de densidade (Figura 5) foram determinados por Souza et al. (2014) em amostras comercializadas na cidade de Belém-PA. Dados mais elevados $(1,106 \mathrm{~g} / \mathrm{mL})$ foram obtidos por Santos (2016) analisando amostras na Cidade de Grajaú-MA.

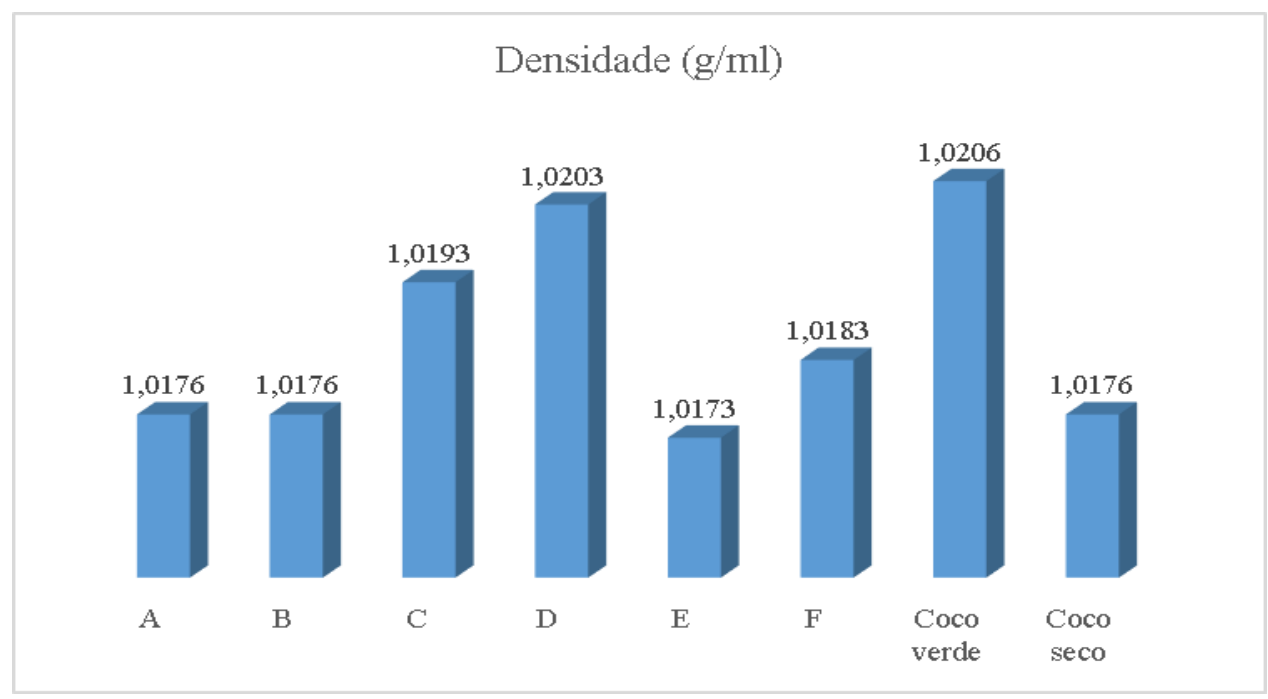

Figura 5. Densidade nas amostras de água de coco. 
A relação SS/AT (Figura 6), de acordo com Chitarra e Chitarra (2005), é fundamental na avaliação da maturidade, do aroma e do sabor do fruto, sendo mais eficiente que a quantificação de açúcares e acidez. No presente trabalho essa relação variou de 5,02 a 8,55. Duarte (2012) encontrou relação mais baixa $(4,03$ a 6,66). Imaizume (2016) e Silva et al. (2013) encontraram valores superiores, possivelmente devido aos baixos valores da acidez total titulável.

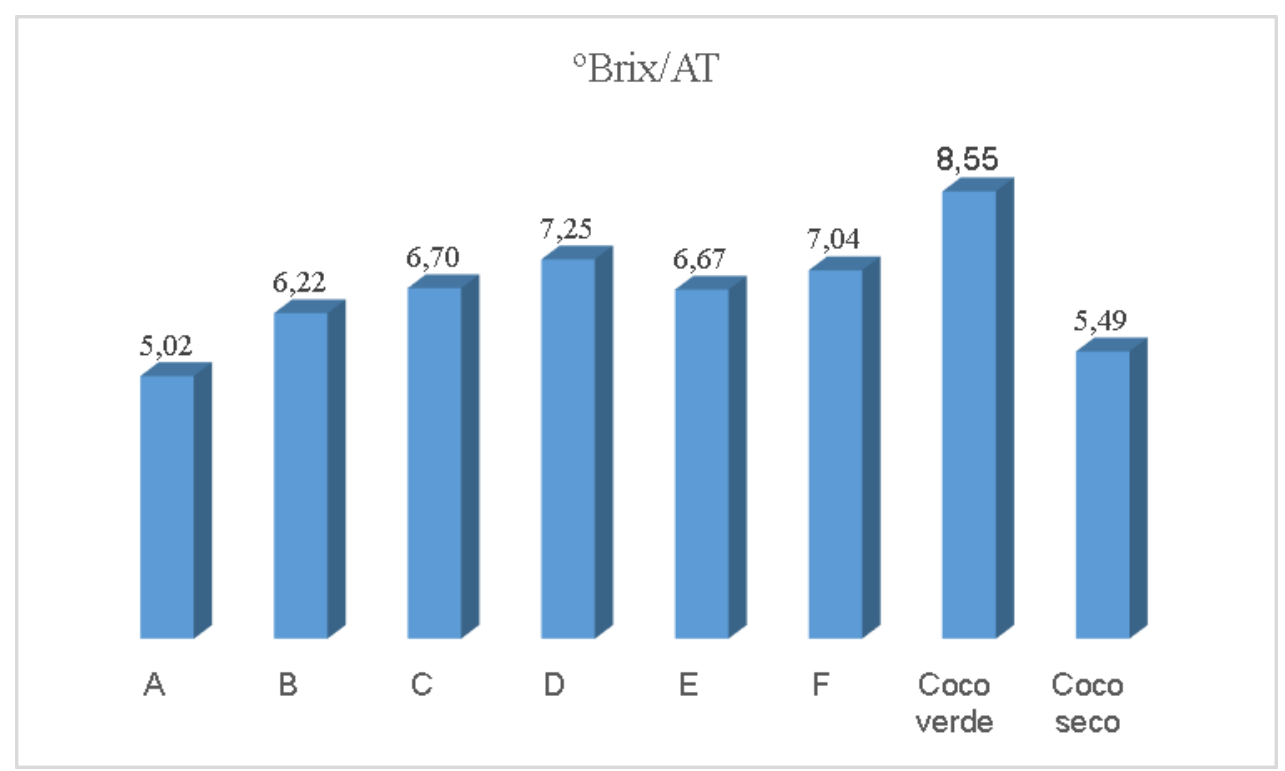

Figura 6. Relação ${ }^{\circ}$ Brix/Acidez Total Titulável.

\section{Conclusão}

De acordo com as análises realizadas nas águas de coco, comercializadas no Município de João Pessoa, todas as amostras estavam dentro dos parâmetros exigidos pela legislação vigente, no que diz respeito ao $\mathrm{pH}$ e aos sólidos solúveis. Convém ressaltar que a Instrução Normativa MAPA no 9/2020 não contempla valores padrões de referência para acidez total titulável, açúcar total e densidade. Tais valores também deveriam ser introduzidos na legislação para que exista um controle mais rígido da qualidade da água de coco consumida. Os órgãos de fiscalização devem estar sempre atentos para evitar que produtos fora dos padrões sejam comercializados e prejudiquem a saúde da população.

\section{Conflito de interesses}

Os autores declaram não haver conflito de interesses.

\section{Referências}

Alves, G. S.; Araújo, E. C. O. N.; Alves, J. E. A.; Silva, P. R. A; Lisbôa, C. G. C. Análises físicoquímicas de águas de coco in natura, envasada e esterilizada comercializadas na Cidade de Salgueiro-PE. Anais do II Congresso Internacional das Ciências Agrárias - COINTER, PDVAgro, 2017. 
Aragão, W. M.; Isberner, I. V.; Cruz, E. M. O. Água-de-coco. Aracaju: Embrapa Tabuleiros Costeiros, 2001. (Documentos, 24). Disponível em: <https://www.infoteca.cnptia. embrapa.br/infoteca/bitstream/doc/370873/1/CPATCDOC.2401.pdf>. Acesso em: 23 ago. 2020.

Aroucha, E. M. M.; Góis, V. A.; Leite, R. H. L.; Santos, M. C. A.; Souza, M. S. Acidez em frutas e hortaliças. Revista Verde de Agroecologia, v. 5, n. 2, p. 1-4, 2010.

Brainer, M. S. C. P. Produção de coco: o Nordeste é destaque nacional. Caderno Setorial ETENE, n. 61, p. 1-25, 2018. Disponível em: <https://www.bnb.gov.br/documents/ 80223/4296541/61_coco.pdf>. Acesso em: 23 ago. 2020.

Brasil. Instrução Normativa MAPA no 27, de 22 de julho de 2009. Estabelece os procedimentos mínimos de controle higiênico-sanitário, padrões de identidade e características mínimas de qualidade gerais para a água de coco. Disponível em: <https://www.gov.br/agricultura/pt-br/assuntos/inspecao/produtos-vegetal/legislacao1/biblioteca-de-normas-vinhos-e-bebidas/instrucao-normativa-no-27-de-22-de-julho-de2009.pdf>. Acesso em: 23 ago. 2020.

Brasil. Instrução Normativa MAPA no 9, de 30 de janeiro de 2020. Disponível em: <https://in.gov.br/web/dou/-/instrucao-normativa-n-9-de-30-de-janeiro-de-2020240823537>. Acesso em: 23 ago. 2020.

Carvalho, J. M.; Maia, G. A.; Sousa, P. H. M.; Maia Jr., G. A. Água-de-coco: propriedades nutricionais, funcionais e processamento. Ciências Agrárias, v. 27, n. 3, p. 437-452, 2006.

Cecchi, H. M. Fundamentos teóricos e práticos em análises de alimentos. 2. ed. Campinas: Editora UNICAMP, 2003.

César, J. M. S.; Petroianu, A.; Vasconcelos, L. S.; Cardoso, V. N.; Mota, L. G.; Barbosa, A. J. A.; Soares, C. D. V.; Oliveira, A. L. Estudo preliminar da água de coco para preservação de enxertos teciduais em transplante. Revista do Colégio Brasileiro de Cirurgiões, v. 41, n. 1, p. 43-48, 2015. https://doi.org/10.1590/0100-69912015001009

Charlo, H. C. O.; Castoldi, R.; Vargas, P. F.; Braz, L. T. Desempenho de híbridos de melão cultivados em substrato. Revista Científica, v.37, n. 1, p. 16-21, 2009.

Chitarra, M. I. F.; Chitarra, A. B. Pós-colheita de frutos e hortaliças: fisiologia e manuseio. Lavras: ESAL/FAEPE, 2005.

Costa, L. M. C.; Maia, G. A.; Costa, J. M. C.; Figueiredo, R. W.; Sousa, P. H. M. Avaliação de água-de-coco obtida por diferentes métodos de conservação. Ciência e Agrotecnologia, v. 29, n. 6, p. 1239-1247, 2005. https://doi.org/10.1590/S1413-70542005000600019

Duarte, C. S. S. Análise físico-química da água de coco (Cocus nucifera): nas formas industrializada e in natura do Município de Ariquemes-RO. Ariquemes: Faculdade de Educação e Meio Ambiente, 2012. (Monografia de graduação).

Ferreira, D. F. Sisvar: A guide for its Bootstrap procedure in muiltiple comparasions. Ciência e Agrotecnologia, v. 38, n. 2, p. 109-112, 2014. https://doi.org/10.1590/S141370542014000200001

Fernando, W. M. A. D. B.; Martins, I. J.; Goozee, K.; Brennan, C. S.; Jayasena, V.; Martins, R. N. The role of dietary coconut for the prevention and treatment of Alzheimer's disease: Potential mechanisms of action. British Journal of Nutrition, v. 114, n. 1, p. 1-14, 2015. https://doi.org/10.1017/s0007114515001452 
Froehlich, A. Água de coco: aspectos nutricionais, microbiológicos e de conservação. Saúde e Pesquisa, v. 8 , n. 1 , p. $175-181$, 2015. https://doi.org/10.17765/1983-1870.2015 v8n1p175-181

Imaizumi, V. M.; Brunelli, L. T.; Sartori, M. M. P.; Venturini Filho, W. G. Análise físicoquímica e energética de água de coco in natura e industrializada. Energia na Agricultura, v. 31, n. 3, p. 298-304, 2016. https://doi.org/10.17224/EnergAgric.2016v31n3p298-304

Instituto Adolfo Lutz. Métodos físico-químicos para análise de alimentos. 1. ed. São Paulo: Instituto Adolfo Lutz, 2008.

Kays, J. S. Postharvest physiology of perishables plant products. New York: AVI, 1991.

Lima, S. A. S.; Machado, A. V.; Cavalcanti, M. T.; Araújo, D. R. Caracterização físico-química de qualidade da água de coco anão verde industrializada. Revista Verde de Agroecologia e Desenvolvimento Sustentável, v. 10, n. 1, p. 35-42, 2015.

Medeiros, V. F. L. Efeitos da água de coco hipertônica e sinvastatina no tratamento da sepse e choque hipovolêmico em ratos. Natal: Universidade Federal do Rio Grande do Norte, 2017. (Tese de doutorado).

Mendonça, L. P.; Melo, E. C. C.; Macedo, R. C. B. S.; Freire, B. C. F.; Santana, F. E. O.; Soares, K. M. P. Caracterização microbiológica, físico-química e de rotulagem de águas de coco envasadas. Research, Society and Development, v. 9, n. 8, e273985299, 2020. https://doi.org/10.33448/rsd-v9i8.5299

Nery, M. V. S.; Bezerra, V. S.; Lobato, M. S. A. Avaliação físico-química de coco anão cultivado no Estado do Amapá. Revista Verde de Agroecologia e Desenvolvimento Sustentável, v. 4, n. 1, p. 45-51, 2002.

Oliveira, H. J. S.; Abreu, C. M. P.; Santos, C. D.; Cardoso, M. G.; Teixeira, J. E. C.; Guimarães, N. C. Carbohydrate measurements on four brands of coconut water. Ciência e Agrotecnologia, v. 27, n. 5, p. 1063-1067, 2003. https://doi.org/10.1590/S141370542003000500013

Pinheiro, A. M.; Machado, P. H.; Costa, J. M. C.; Maia, G. A.; Fernandes, A. G.; Rodrigues, M. C. P.; Hernandez, F. F. H. Caracterização química, físico-química, microbiológica e sensorial de diferentes marcas de agua de coco obtidas pelo processo asséptico. Revista Ciência Agronômica, v. 36, n. 2, p. 209-214, 2005.

Rosa, C.; Ferrandin, D.; Chaves, M. A. Características microbiológicas e físico-químicas de diferentes maracas de água de coco esterilizadas. Anais do VII Simpósio de Alimentos para a Região Sul, Passo Fundo, v. 7, p. 2-7, 2011

Rosa, M. F.; Abreu, F. A. P. Água-de-coco: métodos de conservação. Fortaleza: Embrapa CNPAT/SEBRAE, 2000. Disponível em: <http://www.ceinfo.cnpat.embrapa.br/arquivos/ artigo_1906.pdf>. Acesso em: 02 set. 2020.

Sampaio, J. A.; Silva, F. A. N. G. Determinação das densidades de sólidos e de polpa. In: Sampaio, J. A.; França, S. C. A.; Braga, P. F. A. (Orgs.). Tratamento de minérios: práticas laboratoriais. Rio de Janeiro: CETEM/MCTI, 2007.

Santos, N. B. Análise físico-química e microbiológica de água de coco comercializada na Cidade de Grajaú-MA. São Luis: Universidade Federal do Maranhão, 2016. (TCC de graduação).

Scott, A. J.; Knott, M. A. A cluster analysis method for grouping means in the analysis of variance. Biometrics, v. 30, n. 3, p. 507-512, 1974. https://doi.org/10.2307/2529204 
Silva, C. E. F.; Moura, E. M. O.; Souza, J. E. A.; Abud, A. K. S. Quality control of tropical fruit pulp in Brazil. Chemical Engineering Transactions, v. 44, p. 193-198, 2015. https://doi.org/10.3303/CET1544033

Silva, D. L. V. Alves, R. E.; Figueiredo, R. W.; Maciel, V. T.; Farias, J. M.; Aquino, A. R. L. Características físicas, físico-químicas e sensoriais da água de frutos de coqueiro anão verde oriundo de produção convencional e orgânica. Ciência e Agrotecnologia, v. 33, n. 4, p. 1079-1084, 2009. https://doi.org/10.1590/S1413-70542009000400019

Silva, L. R.; Barreto, N. D. S.; Mendonça, V.; Braga, T. R. Características físicas e físicoquímicas da água de frutos de coqueiro anão verde. Revista Brasileira de Tecnologia Agroindustrial, $\quad$ v. 7, $\quad$ n. 2, p. 1022-1032, 2013. https://doi.org/10.3895/S198136862013000200002

Souza, E. C.; Barbosa, I. C. C.; Rosa, R. M. S. S.; Silva, E. R. M.; Silva, A. S. Avaliação físico-química de águas-de-coco submetidas a processos industriais e in natura comercializadas na Cidade de Belém-PA. Anais do 54ํㅡㄹ Congresso Brasileiro de Química, Natal, 2014.

Tan, T.-C.; Cheng, L.-H.; Bhat, R.; Rusul, G.; Easa, A. M. Composition, physicochemical properties and thermal inactivation kinetics of polyphenoloxidase and peroxidase from coconut (Cocos nucifera) water obtained from immature, mature and overly-mature coconut. Food Chemistry, v. 142, p.121-128, 2013. https://doi.org/10.1016/ j.foodchem.2013.07.040

Vasconvelos, B. M. F.; Oliveira, V. N. S.; Silva, I. B. M.; Soares, S. E.; Costa Filho, G. D.; Vaez, J. R. Qualidade físico-química da água de coco comercializada por ambulantes no Município de Mossoró/RN. Química: Ciência, Tecnologia e Sociedade, v. 4, n. 2, p. 81-92, 2015.

Venturini Filho, W. G. Tecnologia em bebidas. 1. ed. São Paulo: Edgar Blücher, 2005.

Informação da Licença: Este é um artigo Open Access distribuído sob os termos da Licença Creative Commons Attribution, que permite uso irrestrito, distribuição e reprodução em qualquer meio, desde que a obra original seja devidamente citada. 